\title{
Relações de gênero e divisão sexual do trabalho no meio rural: interlocuções com o movimento social "Marcha das Margaridas"
}

\author{
Raquel Quirino Gonçalves ${ }^{1}$, Soraia de Mello Guimarães ${ }^{2}$ \\ ${ }^{1}$ Centro Federal de Educação Tecnológica de Minas Gerais - CEFET. Programa de Pós-Graduação em Educação \\ Tecnológica. Avenida Amazonas, 7675, Bairro Nova Gameleira. Belo Horizonte - MG. Brasil. \\ quirinoraquel@ hotmail.com. ${ }^{2}$ Centro Federal de Educação Tecnológica de Minas Gerais - CEFET.
}

RESUMO. O presente artigo problematiza as relações de gênero e a divisão sexual do trabalho no meio rural dialogando com o movimento social "Marcha das Margaridas". Tendo como sujeitos de pesquisa mulheres produtoras rurais, do norte do Estado de Minas Gerais, participantes da Marcha, por meio de uma observação participante, entrevistas e relatos de experiências buscou-se desvelar os sexismos presentes nas relações de trabalho no campo e as mudanças auferidas na prática social e na visão de mundo dessas mulheres. Os achados revelam que, não obstante, ainda as situações de desigualdades e a invisibilidade das mulheres presentes no trabalho meio rural com a permanência do "trabalho múltiplo", a participação e o engajamento em movimentos sociais de base feminista e rural, tais como a "Marcha das Margaridas", têm contribuído para a quebra de paradigmas enraizados na sociedade. Evidenciam-se alterações na forma de pensar e de ver o mundo, bem como na prática social, o que traz conquistas substanciais para as mulheres do campo.

Palavras-chave: Divisão Sexual do Trabalho no Meio Rural, Relações de Gênero, Movimento Social. 


\title{
Gender relations and sexual division of labor in the countryside: interlocutions with the social action "Marcha das Margaridas"
}

\begin{abstract}
This article discusses gender relations and the sexual division of labor in the countryside, in dialogue with the social action "Marcha das Margaridas". Having as research subjects countryside women from the north of Minas Gerais State, participants of the "Marcha", by means of participant observation, interviews and informal conversations, sought to unveil the sexism present in labor relations in the countryside and the changes that occurred in the social practice and the worldview of these women. The findings reveal that, despite the situations of inequalities and invisibility of women in the countryside labor - with the persistence of "multiple tasks", participation and engagement in feminist and countryside social actions such as The "Marcha das Margaridas", have contributed to the breakdown of paradigms rooted in society. There are changes in the way of thinking and seeing the world, as well as in social practice, which brings substantial achievements to the countryside women.
\end{abstract}

Keywords: Sexual Division of Labor in the Countryside, Gender Relations, Social Action. 


\title{
Relaciones de género y división sexual del trabajo en el medio rural: interlocuciones con el movimiento social "Marcha das Margaridas"
}

\begin{abstract}
RESUMEN. Este artículo analiza mediante el diálogo con el movimiento social "Marcha das Margaridas", las relaciones de género y la división sexual del trabajo en el medio rural. Por medio de la observación participante, entrevistas y conversaciones informales, y teniendo como sujetos de estudio a mujeres productoras rurales del norte del Estado de Minas Gerais y miembros de la Marcha, se buscó desvelar los sexismos presentes en las relaciones de trabajo en el campo, y los cambios obtenidos en la práctica social y en la visión del mundo de esas mujeres. Los hallazgos revelan que, aunque aún hay situaciones de desigualdad y la invisibilidad de las mujeres presentes en el trabajo rural, con la persistencia del "trabajo múltiple", la participación y el compromiso de movimientos sociales de base feminista y rural tales como la "Marcha das Margaridas", ha habido una contribución para la ruptura de paradigmas enraizados en la sociedad. Se evidencian cambios en la forma de pensar y de ver el mundo, así como en la práctica social, lo que trae conquistas substanciales para las mujeres del campo.
\end{abstract}

Palabras-clave: División Sexual del Trabajo en el Medio Rural, Relaciones de Género, Movimiento Social. 


\section{Introdução}

As dificuldades enfrentadas pelas mulheres no mundo do trabalho são historicamente marcadas pelo sexismo presente na sociedade, de maneira geral, e nas relações do trabalho produtivo, especificamente. Em se tratando da mulher trabalhadora do meio rural, tais situações se exacerbam diante de sua dificuldade ao acesso aos benefícios sociais, ao crédito, à assistência técnica e à formação profissional, além da grande disparidade econômica presente nos indicadores oficiais de trabalho e renda.

Historicamente no Brasil as relações de trabalho no meio rural apresentam uma realidade de extrema precarização, com salários e direitos muito aquém daqueles auferidos pela sociedade em geral, agravando-se para a mulher lavradora que têm múltiplas jornadas, dividindo-se entre os cuidados com a casa e a família e o trabalho na lavoura, tendo, muitas vezes, sua contribuição produtiva e econômica invisível na trama das relações sociais. Conforme dados do II Plano Nacional de Políticas para Mulheres (Brasil, 2015, p. 34), as jornadas de trabalho declaradas por homens e mulheres na atividade agropecuária demonstram claramente a invisibilidade do trabalho feminino no espaço rural. Contudo, diante da precariedade do trabalho no campo, as mulheres vêm demarcando seus espaços com estratégias de resistência, por meio dos movimentos sociais.

Nesse contexto, o presente artigo, resultado de uma pesquisa de mestrado em educação, investiga a divisão sexual do trabalho e as relações de gênero no meio rural, tendo como interlocução a Marcha das Margaridas, movimento social de base feminista, formado por mulheres do campo para se reafirmarem como cidadãs de direitos. Identifica e analisa, em seus limites, as contribuições do movimento na constituição da visão de mundo e na prática social dessas mulheres lavradoras participantes da Marcha no município de Porteirinha, cidade situada ao norte do Estado de Minas Gerais.

Trata-se de uma pesquisa qualitativa (Alves-Mazzotti \& Gewandsznajder, 1999), na qual as construções teóricas para análise dos dados empíricos foram fundamentadas na Sociologia do Trabalho Francesa, fortemente influenciada pelos pressupostos marxistas. Basicamente os conceitos sobre divisão sexual do trabalho, apresentados por Hirata (1998; 2002; 2007; 2009) e Kérgoat (1986; 1996; 2003; 2009) fundamentam esta pesquisa. Os dados empíricos foram levantados a partir de observações participantes, de entrevistas semiestruturadas e relatos de experiências com mulheres lavradoras participantes da 
Marcha e com a líder sindical do movimento. Destaca-se neste estudo a utilização de técnicas da pesquisa etnográfica, pois visa à descrição detalhada dos fatos, da visão de mundo e dos conflitos dos sujeitos envolvidos (Velho, 1978).

\section{A divisão sexual do trabalho e as relações de gênero no meio rural}

Segundo Héritier (1997, p. 24), nas sociedades pré-históricas já havia um padrão de organização social baseado na repartição distinta de tarefas entre homens e mulheres. Nesse período surge a forma de subjugação de um sexo pelo outro, como proclamação de um conflito entre os sexos, até então, ignorado na pré-história.

Para Quirino (2011, p. 43),

... evidencia-se, ainda que não de forma declarada, certo determinismo biológico, pelo qual se deduziria que as mulheres no trabalho são inferiores por natureza e que a sua submissão na sociedade tem uma base concreta na sua conformação biológica. Portanto, difícil ou mesmo impossível de ser suplantada.

Conforme afirma Engels (1977, p. 70-71), “... a primeira divisão do trabalho é a que se fez entre o homem e a mulher para a procriação dos filhos", evidenciando, dessa forma, a opressão de classes e de sexos:
... o primeiro antagonismo de classes que apareceu na história coincide com o desenvolvimento do antagonismo entre o homem e a mulher na monogamia; e a primeira opressão de classes, com a opressão do sexo feminino pelo masculino. (Engels, 1977, p. 70-71).

Todavia, para Engels, a raiz material da opressão da mulher não tinha como causa básica a constituição do corpo, mas era fruto de determinadas relações sociais que se assentavam na divisão do trabalho e na exploração de uns pelos outros.

Também Carreira (2004, p. 15) esclarece que
a categoria gênero também contribui para revelar, a partir de uma grande lente, aquilo que é cultural e, logo pode ser mudado na vida em sociedade, questionando a naturalização da desigualdade social entre os sexos. Ao mostrar a dimensão da desigualdade social da desigualdade e suas repercussões na divisão sexual do trabalho, escancara ainda mais portas e janelas para a ação política de coletivos, organizações e movimentos que atuam pela transformação dessa realidade.

Da mesma forma, Quirino (2011, p. 44) complementa afirmando que, "a questão da opressão da mulher deixa de ser do domínio da biologia e é inserida no domínio da história, da cultura, tornando possível assim vislumbrar a sua superação por meio da ação política, pois se não é algo natural, pode ser superada". 
Destarte, a divisão sexual do trabalho para Hirata e Kérgoat (2001, p. 599) é

... a forma de divisão do trabalho social decorrente das relações sociais entre os sexos; mais do que isso, é um fator prioritário para a sobrevivência da relação social entre os sexos. Essa forma é modulada histórica e socialmente. Tem como características a designação prioritária dos homens à esfera produtiva e das mulheres à esfera reprodutiva e, simultaneamente, a apropriação pelos homens das funções com maior valor social adicionado (políticos, religiosos, militares etc.).

Ressalta-se nesse contexto de divisão do trabalho, que as atividades realizadas pelas mulheres nos espaços privados não são consideradas como trabalho de grande importância e sem relevância econômica, visto apenas como ajuda e, com isso, o trabalho produtivo é algo que não lhe cabe.

Tal divisão também é evidenciada no meio rural, nos estudos de Schwendller (2002, p. 2), pois, desde muito cedo, os meninos e as meninas aprendem determinadas funções específicas.

A educação na família constitui-se num importante espaço de construção de gênero, onde os pais educam as meninas e os meninos para determinadas funções sociais, gostos, competências. Na cultura do campo, geralmente, a menina aprende com a mãe, as lidas de casa, os cuidados para com os filhos, o preparo da horta, aprendendo raramente, a discutir política, planejar a produção, negociar e comercializar o produto. Isto cabe ao filho homem, o qual também, muitas vezes, não aprende as lidas da casa e o cuidado com as crianças.

A divisão dos papéis entre homens e mulheres se constrói, assim, dentro dos lares por meio da divisão do trabalho, no qual as tarefas domésticas realizadas pelas mulheres não são reconhecidas como trabalho e, “... mesmo a mulher participando do trabalho produtivo, este é muitas vezes visto como uma 'ajuda" (Shwendller, 2002, p. 2). No entanto, para o mesmo autor, no meio rural, a mulher possui uma presença participativa na esfera pública, trazendo sua contribuição no trabalho, nos movimentos sociais e na educação. E, nas abordagens de Pacheco (2002, p. 143), urge a necessidade da mulher trabalhadora do campo ter $\mathrm{o}$ reconhecimento do seu trabalho, pois, “... o paradigma dominante na economia reforça essas desigualdades duplamente: ignora o trabalho reprodutivo não pago, tornando invisível a maior parte do trabalho feminino, e ignora a divisão sexual do trabalho".

Destaca-se, nesse contexto, a múltipla jornada de trabalho assumida pela mulher do meio rural, que passa o dia todo na lavoura, no fim da tarde retorna ao lar assumindo os afazeres da casa e os cuidados com os familiares e, na maioria dos casos, ainda se dedica aos movimentos 
sociais e a trabalhos comunitários (Salvaro, 2004, Melo, 2001).

Nessa divisão de trabalho, segundo Abramovay (2000, p. 348-349), a mulher é responsável pela reprodução social do seu grupo familiar, tanto no trabalho doméstico, quanto na força de trabalho produtivo. A mulher no meio rural exerce funções de adubação, capinação, colheitas, podas, secar, malhar, ensacar o feijão (e outros grãos), cuidar das pequenas criações, torna-se responsável por todo trabalho ao seu entorno etc. No entanto, não obstante sua relevância na produção agrícola, seu trabalho ainda permanece invisível. Nesse mesmo contexto,

subestimam-se e desconhecem a presença do trabalho feminino na População Economicamente Ativa (PEA) agrícola, na medida em que grande parte dessas mulheres trabalha ajudando a unidade familiar, sem uma remuneração específica. Os trabalhos considerados ajuda são tipicamente femininos, que, por não serem trocados no mercado, não tem valor por si mesmo, mas contribuem para a produção geral da força do trabalho (Abramovay, 2000, p. 349).

$\mathrm{Na}$ agricultura a divisão sexual do trabalho e as relações entre homens e mulheres não são construídas com base nas características biológicas, mas num produto social que legitima as relações de poder que se forma no processo histórico e pode ser transformado. A autora cita algumas dificuldades enfrentadas pelas mulheres produtoras rurais, tais como, a limitação de crédito para agricultura, capacitação, entre outros fatores que favorecem a invisibilidade da mulher.

\section{Os movimentos sociais rurais e a Marcha das Margaridas}

Para Gohn (2011, p. 335), os movimentos sociais são “... ações sociais coletivas de caráter sociopolítico e cultural que viabilizam formas distintas da população se organizar e expressar suas demandas". As ações populares defendem seus interesses de várias formas e se transformam no tempo e no espaço, por meio de uma inquietação e insatisfação de um determinado coletivo social. Dessa maneira,

\begin{abstract}
os movimentos realizam diagnósticos sobre a realidade social, constroem propostas. Atuando em redes, constroem ações coletivas que agem como resistência à exclusão e lutam pela inclusão social. Constituem e desenvolvem o chamado empowerment de atores da sociedade civil organizada à medida que criam sujeitos sociais para essa atuação em rede (Gohn, 2011, p. 336).
\end{abstract}

No Brasil, segundo Foschiera (2004), o meio rural continua sendo local de muitos embates sociais. A luta pela terra por aqueles que não a possuem e para quem as ocupa cria uma tensão permanente entre os sem terra e posseiros de um lado e os latifundiários de outro. Nesse cenário, segundo Grzybowski (1987, p. 17) as mobilizações de massa de trabalhadores rurais já eram comuns no período anterior ao Golpe Militar de 1964, 
através da Liga das Camponesas (Nordeste), das Associações de Lavradores e Sindicatos (Nordeste, Sudoeste e Goiás) e do MASTER (Rio Grande do Sul). Embora as ligas camponesas tenham inserido a reforma agrária na discussão no âmbito da política e da academia e se transformaram em instrumentos da luta de massas no Brasil, como eram filiadas ao Partido Comunista Brasileiro PCB, não adquiriram durabilidade e relevância (Ribeiro, 2010, p. 31).

$\mathrm{Na}$ mesma luta pelos direitos dos lavradores e camponeses, nas décadas de 1970-1980, a produtora rural Margarida Alves, destacou-se na luta pelos direitos das mulheres do campo, cuja história de lutas e morte trágica inspirou e ainda inspira, trabalhadoras rurais em todo Brasil. Nascida em 05 de Janeiro de 1933, em Alagoas Grande, Estado de Pernambuco, era sindicalizada e foi eleita como presidente do Sindicato Rural em 1973. Em 12 de Agosto de 1983 foi assassinada com um tiro no rosto na porta de sua casa. Este fato comoveu, não só os produtores rurais, mas também a opinião pública de todo o país e, a partir de então, Margarida Alves tornou-se o símbolo de luta das mulheres rurais.

Assim, a "Marcha das Margaridas", movimento social inspirado na luta de Margarida Alves, “... surgiu da grande necessidade que as mulheres trabalhadoras rurais do campo e da floresta têm pela igualdade de gênero". (Fernandes, 2012, p. 31). Trata-se de uma ampla ação estratégica das mulheres do campo, da floresta e das águas, para conquistar visibilidade, reconhecimento social e político e cidadania plena.

Organizada pela Confederação Nacional dos Trabalhadores na Agricultura CONTAG, Federações e Sindicatos, a primeira Marcha das Margaridas ocorreu ano 2000, no período de governo do então Presidente Fernando Henrique Cardoso, com forte denúncia ao projeto neoliberal de governo que atingia diretamente o meio rural, apresentando uma pauta de reivindicações para negociação. Esta marcha aliou-se à Marcha Mundial das Mulheres, com razões para marchar contra a fome, a pobreza e a violência sexista. (CONTAG, 2015).

Em seguida, se firmou na agenda do Movimento Sindical de Trabalhadores e Trabalhadoras Rurais - MSTTR. Realizada, bianualmente, a partir do ano 2000, a Marcha agrega mulheres de todo o país que saem em peregrinação de suas regiões e vão até Brasília para reivindicar seus direitos e se consolidou na luta contra a fome, a pobreza e a violência sexista no campo, apresentando uma pauta de reivindicações para negociação contando hoje com mais de 20.000 participantes (CONTAG, 2015). 
Como resultado das manifestações da "Marcha das Margaridas" realizadas no Brasil, para garantir o acesso a terra e à sua documentação, dar apoio às mulheres assentadas e à produção da agricultura familiar, foi criado o Programa Nacional de Documentação da Trabalhadora Rural PNDTR (com unidades móveis em todos os estados), por meio do qual foram atendidas mais de um milhão de mulheres. Dentre as maiores conquistas das mulheres por meio da "Marcha das Margaridas", destaca-se também a Titulação Conjunta Obrigatória da Terra - Edição da Portaria 981 de 2 de outubro de 2003 que, em decorrência hoje, mais de $70 \%$ dos títulos de terra emitidos têm a mulher como primeiro titular ${ }^{\mathrm{i}}$.

Em sua edição no ano de 2015 a Marcha, ocorrida nos dias 11 e 12 de agosto, reuniu mulheres de todas as regiões do Brasil com o intuito de reafirmar e ampliar políticas públicas para o repasse de recursos para vencer a pobreza, a desigualdade, a opressão e violência no campo, para assegurar o respeito e a qualidade de vida, o desenvolvimento sustentável, proteção social, educação, saúde e previdência social, além de garantia de trabalho, relações de trabalho justas, em especial para mulheres trabalhadoras rurais.

\section{Relato da observação participante}

No dia 08 de agosto de 2015 cheguei à cidade de Porteirinha e fui recebida pela Presidenta do Sindicato dos Agricultores do Norte de Minas, Maria de Lourdes, pequena produtora rural da região. Percorremos mais $18 \mathrm{~km}$ de estrada de terra para chegar até sua fazenda. Pude perceber que o local possui vegetação semiárida, as propriedades na região passam por sérios problemas devido à seca, o que dificulta o plantio e a criação de animais.

A líder sindical foi muito acolhedora e pediu que eu ficasse próxima dela durante a realização de suas atividades domésticas. Conversamos sobre vários assuntos relacionados ao Coletivo de Mulheres do meio rural e a Marcha das Margaridas do Norte de Minas Gerais. Assim relata:

Em 2009, nessa organização a gente foi conversando e ampliando as conversas com as mulheres. Nós resolvemos, com o desafio da violência com as mulheres e esses impactos ambientais que há muito tempo vem afligindo a gente. A gente resolveu fazer uma passeata: a marcha em 2007 em Montes Claros pra reivindicar $\mathrm{o}$ respeito às mulheres, o combate à violência e as questões ambientais. Organizamos pra fazer uma Marcha com 300 mulheres e lá nós colocamos mais de 400 mulheres. Em 2010 fizemos a segunda Marcha aqui na Serra Geral, abrangendo Nova Porteirinha e Janaúba. Preparamos pra fazer com 
500 e fizemos com 1000 mulheres. Em 2011 nós realizamos a terceira. Foi lá "ne" Taiobeiras com 2000 mulheres. Em 2013 foi realizada em Porteirinha com 3.000 mulheres. Em 2014 nós fizemos duas pequenas com 500 mulheres. Uma em Indaiabira e fizemos uma em Ibiracatu com 500 mulheres num movimento nunca visto pelo Município. Não tinha como fazer grande, por causa que o município não tinha estrutura, aí tínhamos que fazer porque estava acontecendo algumas coisas lá, e tinha que chamar a atenção na questão de violência, agressões, desrespeito com as mulheres (sic).

Durante as nossas conversas Maria de Lourdes evidenciou sua preocupação com o desenvolvimento da região, pois instalaram uma mineradora a 300 metros das plantações da cidade de Janaúba e as consequências ambientais já têm ocorrido na região.

No dia seguinte nos reunimos na sede do Coletivo das Mulheres em Porteirinha, local bem amplo e onde funciona também a Secretaria de Agricultura de Porteirinha. De lá partiu os dois ônibus que nos levariam até Brasília. Ao iniciarmos a viagem, as mulheres se uniram em oração e com cânticos regionais seguimos viagem. Foi uma viagem longa e difícil, em ônibus precários e estradas esburacadas, porém, via-se nos rostos das mulheres o entusiasmo e a esperança. Depois de $814 \mathrm{~km}$ percorridos chegamos a Brasília no dia 11 de agosto para participar da Quinta Marcha das Margaridas.
Aproximadamente 70.000 lavradoras e produtoras rurais chegaram de suas cidades em caravanas e, na Capital Federal, ficaram alojadas no Estádio Mané Garrincha. Também houve grande presença de homens - companheiros sindicalistas, maridos, filhos e amigos das mulheres da Marcha. Cada pessoa era cadastrada pelos organizadores do evento e recebia uma pulseira com o nome, número de seu CPF e sua região de origem. Os corredores do estádio foram divididos por andares e cada Estado ocupava um determinado andar, no qual os banhos eram tomados em banheiros coletivos e a comida preparada e servida para todos. $\mathrm{Na}$ parte térrea ficaram expostos e à venda os trabalhos manuais das mulheres, evidenciando a riqueza e a diversidade cultural do Brasil.

Aproximei-me de algumas mulheres e disse que gostaria de conversar com elas sobre o que estavam achando da Marcha, das instalações etc.

Na chegada eu achei que faltou um pouquinho de organização, mas quanto a instalação a gente sabe que é um pouco complicado. Aonde que eles vão colocar tanta mulher? A gente sabe que um evento deste tamanho tem um custo muito alto. É impossível hospedar este monte de pessoas. A gente sabe que não tem outra alternativa, né? Só deles disponibilizarem um espaço desses, a gente entende que eles quer contribuir da melhor maneira possível. As mulheres vieram aqui 
com um propósito, então tem que aguentar... (sic)

Nem tudo é flores. Assim como nós passamos dificuldades no campo, aqui também passamos por dificuldades. Nós viemos aqui pra trazer uma pauta pro governo, dizer que bom, não está não. Nós não temos outra alternativa (sic).

No dia 11 de agosto houve um encontro dos líderes sindicais, no qual havia um palanque para que as diversas questões fossem discutidas e as pautas de reivindicações apresentadas. $\mathrm{Na}$ ocasião, Maria Ednalva da Silva, da Secretaria de Mulheres da Federação dos Trabalhadores na Agricultura, declarou em seu discurso que o encontro, embora composto por mulheres de regiões tão diferentes do país, apresentavam demandas muito parecidas. Destacou que,

sejam mulheres do meu estado ou de outro, a luta é a mesma, o mesmo objetivo, a mesma dificuldade, tudo é comum. A diferença é a forma de trabalhar, umas com a uva, outras com a maçã, aqui na minha região a gente trabalha com a mandioca, com a fava. A luta em si é pela mesma causa, o mesmo objetivo.

Nesse encontro compareceram o ex Presidente Lula, o Senador Patrus Ananias e outros líderes sindicais: Alessandra da Costa Nunes, Coordenadora Geral da Marcha das Margaridas no Brasil; Coordenadores Regionais da Central dos Trabalhadores Brasileiros; Coordenadores da Central Única dos Trabalhadores; Coordenadores do Partido dos Trabalhadores e a representante da Marcha Mundial das Mulheres. Nessa mesma noite houve vários discursos políticos, inclusive dos Presidentes dos Sindicatos CTB, CONTAG e do Ministro Miguel Rossetto.

No dia seguinte acordamos às 04h30min da manhã e encontramos o grupo das Mulheres da Marcha Mundial que lutam pela diversidade sexual, que batiam em latas para um chamado para todas se unirem em forma ritmada. A Marcha iniciou-se às 09h00min horas e cada estado saiu em blocos guiados por um caminhão com caixas de som e microfones, com os representantes dos sindicatos, percorrendo as ruas de Brasília.

Marchei uma boa parte no bloco de Minas Gerais, aquele momento se tornou histórico, afinal, haviam 70.000 mulheres marchando para mudar nossas políticas em prol das brasileiras, era muito emocionante. Quando chegamos a frente ao Palácio do Planalto as mulheres ergueram suas bandeiras e gritaram palavras de ordem. Conversei com uma participante e perguntei a ela o que havia achado da Marcha.

Ótima muito boa. Acho que foram mais de 100.000 mulheres. É a quarta vez que participo, com muita honra, graças a Deus. Estou aqui e quero continuar e se precisar estarei aqui de novo. Não desistir. Mesmo com as 
dificuldades vou lutar que nós chegamos lá. Nossa, eu adoro a marcha (sic).

Retornamos após a Marcha para o Estádio Mané Garrincha e aguardamos o pronunciamento da Presidenta. A então Presidenta Dilma Rousseff e, após ler a pauta das mulheres, realizou um discurso, no qual ressaltou:

mulheres decididas a batalhar juntas por um mundo melhor. Decididas a avançar nos direitos. Decididas a repudiar a injustiça aqueles que menosprezam as mulheres. Decididas a lutar por mais autonomia e contra qualquer opressão. Decididas a reafirmar o poder das Margaridas de construir nossa história. Vocês inspiram a mim e a todas as mulheres do Brasil, no ato político do encerramento da Marcha das Margaridas 2015, no estádio Mané Garrincha, em Brasília (sic).

A Presidente Dilma fez um apanhado de todas as conquistas das mulheres desde a Marcha realizada em 2011 durante o seu primeiro governo e ressaltou que a discussão sobre a construção de políticas públicas para direitos e igualdades é primordial.

Foi à demanda de vocês que eu tive a honra de transformar em políticas no meu governo, como as 54 unidades móveis em todos os Estados, próximos às mulheres, para enfrentar a violência. Evidenciou também que a Lei Maria da Penha - que torna crime qualquer violência contra as mulheres e o feminicídio -, completou nove anos de vigência naquele ano, sendo também uma das conquistas da Marcha das Margaridas.

Com palavras de ordem: "Intolerância zero com a violência contra as mulheres", a Presidenta anunciou a implantação de "Patrulhas Rurais Maria da Penha" e a nomeação de 10 mil promotoras de justiça, com o objetivo de combater a violência contra as mulheres do campo. "Nós devemos cuidar, e muito, para que o combate à violência seja igual em todas as regiões do país", ressaltou a então Presidenta. Além disso, ressaltou a necessidade de uma formação profissional mais adequada às trabalhadoras do campo pelo Pronatec (Programa Nacional de Acesso ao Ensino Técnico e Emprego) e prestou uma homenagem a duas trabalhadoras rurais que faleceram de morte natural durante a realização da Marcha das Margaridas. A então Presidenta encerrou sua fala recitando versos de uma canção do cantor Lenine. "Os bons momentos da vida, e nos maus tempos da lida. Eu envergo, mas não quebro". "Sou que nem as Margaridas, envergo, mas não quebro".

Saímos de Brasília às 19h00min horas e chegamos a Porteirinha por volta das 10h30min. Retornei a Belo Horizonte com uma grande emoção, pois nunca tinha vivenciado situação semelhante. Aprendi que essas mulheres guerreiras, não 
obstante sua pobreza e vítimas de tantas situações adversas são cheias de vida e de saberes, e não medem esforços para mudar as suas vidas e a vida de todas as mulheres do país, sobretudo aquelas que vivem no meio rural. Voltei me sentindo agradecida por fazer parte desse momento histórico do país.

\section{As mulheres lavradoras e seus discursos}

Durante a visita a Porteirinha e no decorrer da Marcha das Margaridas, mulheres produtoras rurais, moradoras da cidade e participantes da Marcha foram entrevistadas. A faixa etária delas está compreendida entre 28 a 67 anos, representando a grande diversidade geracional de participantes desse movimento social, casadas e viúvas, todas com filhos. Criam gado, animais domésticos de pequeno porte para consumo próprio, cultivam turgo, feijão, milho, mandioca, hortaliça, sementes, frutas, fabricam queijo e fazem artesanatos.

Com exceção da Presidente do Sindicato, Maria de Lourdes, que autorizou a sua identificação, para preservar a identidade das entrevistadas foram utilizados nomes fictícios, a saber: Elizabeth, Ana Maria, Josefina, Adelina, Mariana, Clarice, Romilda, Donata, Efigênia, Fátima e Beatriz.
As questões levantadas não seguiram um roteiro prévio estruturado, mas apenas tópicos a serem discutidos com as mulheres, de forma a evidenciar como tem se dado sua participação na Marcha e de que maneira essa participação tem impactado em sua vida e promovido alterações e/ou contribuições para a constituição de sua prática social.

Gallo (2009, p. 13), ao tentar desvendar como o ser humano concreto produz suas ideias acerca do mundo, se valeu das teorias de Marx e Engels na Ideologia Alemã (1845, p. 28-28), de forma que "o modo de vida pelo qual os homens produzem seus meios de vida depende, antes de tudo, da natureza dos meios de vida já encontrados e do que tem de reproduzir". Para Marx e Engels, o que determina a forma e o modo de vida do ser humano são as suas produções e como elas são produzidas. Assim, as condições materiais determinam em grande medida os sujeitos que são.

Tais assertivas são corroboradas pelas falas das lavradoras quando exaltam seu trabalho junto à natureza, seus artesanatos, seu amor a terra e ao trabalho, sua união na cooperativa e no coletivo de mulheres. Também quando evidenciam as injustiças a que são submetidas e o quanto a união no movimento possibilita estratégias de resistência. 
A gente planta milho, feijão, verduras, cria galinhas, porcos e tudo o que a gente precisa. A terra dá a gente vida (Ana Maria) (sic).

Fiquei na Cooperativa do Grande Sertão fazendo papel de mobilizadora das comunidades no fornecimento de frutas. Foi outra coisa bacana, nós fazíamos a rota e passávamos de caminhão recolhendo as frutas. Eram Umbú, Manga, Siriguela, Acerola, Tamarindo daqui do Sertão. ((Adelina) (sic).)

Ainda na Ideologia Alemã, Marx e Engels (1984, p. XXIV), afirmam que "a humanização do ser biológico específico só se dá dentro da sociedade e pela sociedade." Dessa maneira, as mulheres criam seus espaços de resistência em prol de melhores condições de vida e se ajudam mutuamente. Tais relações promovem o seu aprendizado político e cultural, alteram suas visões de mundo e as tornam mais críticas em relação à vida que vivem e impactam em sua prática social:

Também nesses espaços a gente cresce muito, tanto quanto na melhor qualidade de vida e renda. É uma discussão que a gente faz também na questão política, hoje não entendemos muito da política, mas antes a gente era muito pior. Aí, a gente tem acesso no âmbito da política brasileira. Ajuda a despertar quanto aos nossos direitos e ajuda também nos nossos deveres, isso graças ao nosso coletivo e nossas Marchas e aí nós conseguimos diferenciar uma coisa da outra. O direito de ser cidadão, o direito de ir i vir e o direito das políticas públicas que antes a gente não conhecia e hoje a gente tem mais conhecimento.
Temos que melhorar muito, ainda desejamos muito mais, isso melhorou muito depois de nossa participação (Elizete) (sic).

Porém, a realidade de uma sociedade sexista e patriarcal embasada na divisão sexual do trabalho e em relações de gênero antagônicas e contraditórias, descritas por Hirata e Kérgoat (2001), evidencia-se:

Principalmente no local de trabalho os homens sempre fazem discriminação. Isso é uma luta que tem sempre de ter. Isso é uma coisa que é mantida com naturalidade, mas nós sabemos e que não aceitamos também. Isso já foi muito comum e natural, mas a gente luta pra ser diferente, que sejamos lideranças e lideranças respeitadas. (Adelina) (sic).

E a divisão sexual do trabalho se manifesta de forma contundente:

Geralmente na maioria a mulher tem a sua tarefa e o homem tem suas tarefas. A maioria trabalha junto. A mulher trabalha na roça, na casa e no sindicato. Mas, meu marido faz as mesmas coisas. Mas, no geral a mulher trabalha, lava, passa vai pra Associação, mas o homem é que vende o produto e faz as compras e a mulher não recebe. Só algumas famílias a mulher recebe e divide as tarefas com o marido (Josefina) (sic).

Tal afirmativa é corroborada por Hirata e Kérgoat (2001, p. 599) quando definem a divisão sexual do trabalho social decorrente das relações sociais entre os sexos. 
Essa divisão e valorização diferenciadas do trabalho do homem e da mulher são corroboradas por Quirino (2015, p. 07), quando afirma que “... na sociedade capitalista atual a mulher padece de uma dupla carga: a opressão, traduzida no preconceito e na marginalização pela sua própria condição feminina e por outro lado, na exploração econômica, por estar inserida na dupla jornada de trabalho como trabalhadora assalariada e doméstica". (grifos da autora).

Romilda, Donata e Josefina retratam que, comportamentos de submissão, falta de formação profissional e desconhecimento de seus direitos ainda são comuns entre as mulheres lavradoras.

Ah, eu, pra mim mudou muita coisa. Tive um conhecimento muito "aproveitativo". E muitas vezes a gente não conhecia e não sabia do direito que a gente tinha. As vezes, a gente ficava calada diante das situações, a gente não tinha como responder. Hoje, a gente tem um conhecimento e pode bater de frente com a situação. (Romilda) (sic).

No entanto, com a participação no Coletivo de Mulheres e na Marcha das Margaridas houve uma grande mudança em suas formas de pensar e, consequentemente, na maneira como vivem. $\mathrm{O}$ relato de Ana Maria retrata essas mudanças:
Hoje, as coisas minha está no meu nome, fiquei viúva há pouco tempo. Mas, antes as coisas era dividida entre eu e meu esposo. Uma parte no nome dele e a outra em meu nome, nós trabalhava em conjunto. Com a formação que nós teve, teve um entendimento de que nós tinha que trabalhar junto. Não eu pegando os direito dele, mas trabalhando junto e dividindo os direito. Às vezes as pessoas falam assim: é tomar o direito. Não é isso. É dividir o direito, trabalhar junto. A mulher ajudando $\mathrm{o}$ esposo e o esposo ajudando a mulher. Aí que a gente continua. Às vezes a cabeça do homem trabalha. Mas, às vezes o pensamento da mulher é mais forte e quando coloca isso em prática, as coisas só pode crescer, né? (Ana Maria) (sic).

Maria de Lourdes, por exemplo, alega que o seu companheiro realiza os afazeres domésticos quase diariamente, pois, devido à sua atividade de coordenação do sindicato e seu ativismo na Marcha, precisa se ausentar muitas vezes da cidade. Assim, identifica-se nesse caso uma ruptura em modelos tradicionais da divisão sexual do trabalho doméstico, promovido, ainda que indiretamente, pela sua atuação nos movimentos sociais.

Assim, na casa quem segura as pontas é Zé. Por causa dos projetos que a gente desenvolve, às vezes eu deixo um pouco a desejar. Mas, não posso cobrar dele que às vezes ele sozinho não dá conta aqui na propriedade, eu viajo muito, agora que tô viajando pouco. Tanto é que você está vendo esta horta e eu dou conta de ajudar um pouco nos finais de semana (Maria de Lourdes) (sic). 
As novas visões de mundo, forjadas a partir das estratégias de resistência e do compromisso social assumido por essas mulheres, fazem com que a vida no meio rural passe por mudanças estruturais levando os jovens a adquirirem outra percepção das mulheres nessa sociedade ainda hostil a elas. A formação profissional necessária se dá diretamente por elas ao trocarem fazeres e saberes, nas pautas de reivindicações e na assistência direta às famílias da região:

São várias as demandas! Até os pequenos animais e a área da agricultura tomaria uma pauta e o tempo dos diretores dos sindicatos tudo. Trabalhar as sementes crioulas, ensinar os filhos a plantar a horta, a agroecologia, acompanhar essas famílias, ensinar o aproveitamento das frutas nativas e cultivadas, mexer com a apicultura, as pequenas barragens, são muitos na região que a gente dá assistência. A demanda é muito grande, isso só na área da agricultura, sem contar o setor político, o debate com as mulheres, a carta de aptidão, a carta do produtor, a presidência do coletivo. Então, é uma demanda muito grande que a gente carrega. Aí não sobra tempo. Meus meninos falam assim: a gente não vê outras pessoas se matando pelo Sindicato igual a vocês. Modéstia aparte, nós temos um trabalho diferenciado, diferenciação de atendimento ao agricultor, entendeu? (Efigênia) (sic).

Em Gallo, assim como em Marx, há a afirmação de que a visão de mundo em geral é constituída por uma determinada classe social que impõe seus valores e formas de pensar às outras, porém, no meio rural essas mulheres, mesmo oriundas de classes mais baixas, têm promovido muitas alterações em seu meio social.

Essa história do sindicato do norte de Minas começou com o coletivo de mulheres. O coletivo surgiu de uma demanda das mulheres agricultoras. A gente achava injusto as mulheres serem pautadas só pra cumprir cota. Não ocupavam nenhum lugar efetivo. Aí, as próprias mulheres se rebelaram: espera aí, nós temos que mudar essa história aqui dentro. Se nós somos importantes, porque só tem três mulheres na suplência? Queremos dobrar a quantidade de mulher na diretoria. Nós conseguimos articular uma assembleia com as mulheres da comunidade como um todo. E conseguimos garantir três na suplência e três mulheres na efetiva. Ai criou-se o coletivo de mulheres. Quando essa discussão começou a tomar rumos, outros municípios começou a seguir a gente. Com tanta mulher precisando de um espaço pra se organizar! Ai, nós falamos, se vocês querem, então vamos fazer um debate. Aí, nós começamos a fazer reuniões. Fizemos um monte de reuniões para saber se era isso mesmo que as mulheres estavam querendo, se eram elas ou se alguém estava buzinando no ouvido delas. Todo lugar que a gente chegava convidava 20 e chegavam 50 mulheres (Beatriz) (sic).

No entanto, não obstante os avanços auferidos, “... tal hegemonia não é fácil de ser mantida: tem que ser conquistada e construída a cada dia. A luta pela hegemonia é uma eterna guerra de 
trincheiras entre as diversas classes sociais (Gallo, 2009, p. 31)”.

Nogueira (2006), ao estudar o trabalho das mulheres operadoras de telemarketing, cunhou a categoria "trabalho duplicado", para explicar o trabalho das mulheres que se dividem entre o trabalho doméstico e o trabalho remunerado. Todavia, as mulheres do meio rural ultrapassam tais fronteiras e realizam um "trabalho múltiplo". Além do trabalho diário nas lavouras e das atividades domésticas, dedicam-se incansavelmente a prover o sustento da família por meio da produção de alimentos, artesanatos e venda nas cooperativas; militam diariamente com presença forte e significativa nos sindicatos, no Coletivo de Mulheres e na Marcha das Margaridas, além de outras atividades de assistências social às famílias da região. E a demanda só tende a aumentar, conforme relata uma das produtoras da região:

Nossa, tem uma produção diversificada demais: artesanato de semente, casca de pau, argila; uma diversidade muito grande. Fabricação de doces de todos os tipos, rapadura, licor de Jenipapo. É muito bacana a produção das mulheres no norte de Minas! Agora, eu te falo a infraestrutura pra toda essa mulherada, não é fácil. A gente se desdobra, dá atenção às famílias, organização das mulheres, é difícil. Estou sofrendo um dilema muito grande, nós temos uma parceirona que trabalha com tratamentos alternativos e colocou três projetinhos pra desenvolver na nossa mão e a gente não tá dando conta de desenvolver. Criou os grupos, mas os grupos não desenvolve, a gente tem que ficar puxando estes grupos, senão não anda. As mulheres já cresceram muito, antes nem saiam da cozinha. Agora não. Elas conversam e falam, contam o que tem pra contar. Mais ainda é muita coisa que a gente tem que dar conta. Tá pesado porque está no norte de Minas Gerais todo e as mulheres vai evoluindo e vai ficando exigente também, né? (Efigênia) (sic).

O crescimento das exigências das mulheres, conforme relata à entrevistada, evidencia, como explica Triviñus (2006, p. 122), que as ações práticas tomadas no mundo influenciam diretamente na capacidade de refletir e na consciência e vice-versa. Para o autor, “... o tipo de prática desenvolvida frente a um determinado fenômeno material origina um reflexo na consciência, relativamente, semelhante ao nível de sua complexidade".

Os discursos ecológicos e críticos de algumas delas ilustram a assertiva:

Mas, a gente já está plantando água, está abastecendo o lençol freático, está entrando pelo solo. A gente é um plantador de água. Quando você deixa de usar o veneno e usa o fogo controlado, já está ajudando; o bagaço que joga no solo, você umedece o solo. As famílias de nascentes, córregos na sua propriedade, quando não faz queimadas e usa as máquinas de forma correta. A água abastece o lençol freático e mantém sua propriedade. Quem planta árvores na beira do rio pra evitar assoreamento são os plantadores de água. A 
discussão é nós estamos plantando água para quem e pra quê? Pra agricultura familiar, pra garantir a sobrevivência, para produzir mais alimentos. E, aí, chegam as grandes empresas. Você planta água por um ano e as grandes empresas consomem a água em um dia. Por isso, esse debate é uma modalidade nova preservar a água que você tem, aí essa história de reivindicar contra a mineradora (Maria de Lourdes) (sic).

Outro ponto importante a ser retratado acerca das mudanças na prática social e na visão de mundo dessas mulheres refere-se à sua formação profissional e à valorização de seus saberes.

Gallo (2009) reconhece que o conhecimento possibilita mudanças nas relações sociais e no processo de desenvolvimento do indivíduo em relação à natureza e o meio que o cerca. As produtoras falam com orgulho dos cursos realizados e dos seus saberes tácitos: "fiz curso no SENAR, de avicultura, extrativismo, vários cursos e tenho muitos certificados (Adelina) (sic)."

Conforme a presidente do sindicato, esses cursos são oferecidos por meio do Coletivo das Mulheres no projeto para capacitação das mulheres do campo. Todavia, o coletivo também dá às mulheres a oportunidade de se capacitarem não somente nesses cursos, como também em outros oferecidos pelas mulheres locais, para profissionalizar as mulheres da região.
Nós participamos das planta medicinal, dos remédios caseiro. Mesmo na comunidade e no município Riacho dos Machado ninguém tá mais procurando farmácia. Hoje, nós temos um espaço que nós trabalhamos com a planta medicinal e a ajuda das companheiras. Hoje, nós faz capacitação pra trabalhar com as plantas e a saúde da mulher (Josefina) (sic).

\section{Considerações finais}

O presente artigo teve o objetivo de discutir e trazer algumas questões relativas às relações de gênero e à divisão sexual do trabalho no meio rural e destacar as contribuições do movimento social "Marcha das Margaridas" na transformação da visão de mundo, na formação profissional e da prática social das mulheres lavradoras da cidade de Porteirinha, localizada ao norte do Estado de Minas Gerais.

Os discursos das entrevistadas evidenciam que são inegáveis as contribuições da Marcha das Margaridas na construção e alteração das visões de mundo e das práticas sociais dessas mulheres. $\mathrm{O}$ ativismo político e social das mulheres de Porteirinha denota que elas estão se tornando sujeitos da própria história, conscientes de seus direitos e deveres. Essas mudanças também foram evidenciadas por esta pesquisadora na observação participante da Marcha de 2015 
e nos relatos de experiências das mulheres residentes na região e atuantes no movimento.

Confirma-se, pelos relatos e modos de vida dessas mulheres, que elas nunca foram vistas e identificadas como trabalhadoras rurais, mas apenas ajudantes do pai ou do marido e, seu trabalho, invisível social e economicamente. Essas mulheres plantavam e produziam, confeccionavam produtos e artesanatos, porém, o lucro das vendas era de seus pais ou maridos. Eram impedidas de sair de casa e de manifestar suas ideias. Não tinham oportunidades de formação profissional e sequer conheciam seus direitos, tampouco tinham informações e coragem para lutar por eles.

Porém, os construtos materiais e simbólicos dessa realidade da vida no campo têm sido alterados paulatinamente pela participação ativa das mulheres nos movimentos sociais. Os debates, reivindicações, trocas de saberes, de desejos e angústias compartilhados por elas, além da formação política e profissional que recebem nesses espaços, têm propiciado alterações substanciais na forma de verem e de viver a vida.

É certo que a violência, a desvalorização e a sobrecarga das mulheres do meio rural - que vivenciam um "trabalho múltiplo", trabalhando em casa, na lavoura, na produção de bens vendáveis e na atuação nos movimentos sociais ainda permanecem como uma realidade difícil de ser mudada. No entanto, traços de mudanças de comportamentos entre elas e de seus companheiros foram evidenciados nessa pesquisa. Não obstante a opressão de gênero e a exploração econômica as quais são submetidas os discursos e práticas das entrevistadas, as mulheres estão adquirindo conhecimentos e empoderamento social e político para que suas vozes sejam ouvidas e essa realidade alterada.

Essa pesquisa não teve a pretensão de esgotar as discussões acerca do tema. Pelo contrário, constitui-se em ponto de partida para outras pesquisas relevantes sobre a temática abordada.

\section{Referências}

Alves-Mazzotti, A. J., \& Gewandsznajder, F. (1999). O Método nas ciências naturais $e$ sociais: pesquisa quantitativa $\mathrm{e}$ qualitativa. São Paulo: Pioneira.

$3^{\text {a }}$ Conferência Nacional de Políticas para Mulheres: autonomia e igualdade para as mulheres. (2013). 130. (S. N. Mulheres, Compilador) Brasília.

Abramovay, M., \& Silva, R. (2000). As relações de gênero na Confederação Nacional de Trabalhadores Rurais (CONTAG). In M. I. Rocha. Trabalho de Gênero: mudanças, persistências e desafios. (p. 347). São Paulo: Editora 34.

Brasil, M. D. (s.d.). PRONATEC Campo: Formação profissional para o fortalecimento da agricultura familiar e o 
desenvolvimento rural sustentável em bases territoriais e agroecológicas. Cartilha. Disponível em http://www.mda.gov.br/sitemda/sites/sitem da/files/user img 23/cartilha\%20 PRONAT E C_baixa.pdf. Acesso em 02 de maio de 2016.

Carreira, D. (2004). Igualdade de Gênero no Mundo do Trabalho: projetos brasileiros que fazem a diferença. São Paulo: Cortez.

CONTAG - Comissão Nacional de Mulheres Trabalhadoras Rurais - CNMTR. (2008). Revista da Marcha das Margaridas 2007.

CONTAG - Comissão Nacional de Mulheres Trabalhadoras Rurais - CNMTR. (2015). Revista da Marcha das Margaridas 2015 .

Foshiera, A. A. (2004). Um olhar sobre os movimentos sociais no campo no Brasil. Interface, (01), 77-85. Disponível em http://revista.uft.edu.br/index.php/interface /article/view/323. Acesso em 20 de março de 2015.

Gallo, S. (2009). Subjetividade, Ideologia e educação. Campinas: Alínea.

Gohn, M. D. (2001). Educação Não Formal e Cultura Política. São Paulo: Cortez.

Gohn, M. D. (2001). Movimentos Sociais e educação. São Paulo: Cortez.

Gohn, M. D. (2011). Movimentos Sociais na Contemporaneidade. Revista Brasileira de Educação, 16(47), 333-361.

Grzybowski, C. (1987). Caminhos e descaminhos dos Movimentos Sociais no Campo. Petrópolis: Editora Vozes.

Helena, L. (2012). Educação Rural em Minas Gerais: Origens, concepções e trajetória da Pedagogia da Alternância e das Escolas Família Agrícola. Educação em Perspectiva, 3, 105-125.

Hirata, H. (2002). Nova Divisão Sexual do Trabalho: Um Olhar Voltado para Empresa e a Sociedade. São Paulo: Boitempo.

Hirata, H., \& Kérgoat, D. (2007). Novas Configurações da divisão Sexual do Trabalho. Caderno de Pesquisa, 37(132), p. 595-609.

Marx, K. (1985). O Dezoito Brumário de Luiz Bonaparte. In Textos escolhidos. São Paulo: Abril Cultural.

Marx, K. (1985). Textos escolhidos. São Paulo: Abril Cultural.

Marx, K. (1986). A Ideologia Alemã (Feuerbach).São Paulo: Hucitec.

Nogueira, C. M. (2006). O trabalho duplicado - A divisão sexual do trabalho e na reprodução: um estudo das trabalhadoras do telemarketing. São Paulo: Expressão Popular.

Nogueira, C. M. (2006). O trabalho duplicado - A divisão sexual do trabalho e na reprodução: um estudo das trabalhadoras do telemarketing. São Paulo: Expressão Popular.

Pacheco, M. E. (2002). sistemas de reprodução: uma perspectiva de gênero. Perspectivas de Gênero: Debates e questões para as ONGs. Recife: GT Gênero .

Quirino, R. (2011). Divisão Sexual do trabalho, gênero, relações de gênero $e$ relações sociais de sexo: aproximações teórico-conceituais em uma perspectiva marxista. Belo Horizonte. Disponível em http://www.portal.fae.ufmg.br//seer/índex. php/trabedu/article/viewFile/2532/1622. Acesso em 24 de setembro de 2015. 
Quirino, R. (2011). Mineração também é lugar de mulher! Desvendando a (nova?!) face da divisão sexual do trabalho na mineração de ferro. Universidade Federal de Minas Gerias, Faculdade de Educação. Belo Horizonte: UFMG.

Ribeiro, M. (2010). Movimento Camponês, trabalho e educação: liberdade, autonomia, emancipação: princípios/fins de formação humana. São Paulo: Expressão Popular.

Schwendler, S. F. (2002). A construção do feminino na luta pela terra e na recriação social do assentamento. Inglaterra: University of Nottingham. Disponível em http://www.landless-voices.org. Acesso em 27 de 05 de 2015.

Toledo, C. (2008). Mulheres: o gênero nos une, a classe nos divide. São Paulo: Sundermann.

Triviñus, A. (2006). A dialética materialista e a prática social. Porto Alegre: Movimento.

Velho, G. (1978). Observando o familiar. Em É. d. NUNES, A aventura sociológica: objetividade, paixão, improviso e método na pesquisa social. (pp. 36-46). Rio de Janeiro: Zahar.

\footnotetext{
i Todas as conquistas da "Marcha das Margaridas" encontram-se disponíveis em: http://www.contag.org.br
}

Recebido em: 26/02/2017

Aprovado em: 21/03/2017

Publicado em: 19/04/2017
Como citar este artigo / How to cite this article / Como citar este artículo:

APA:

Quirino, R.. \& Guimarães, S. M. (2017). Relações de gênero e divisão sexual do trabalho no meio rural: interlocuções com o movimento social "Marcha das Margaridas". Rev. Bras. Educ. Camp., 2(1), 231-251. DOI: $\quad$ http://dx.doi.org/10.20873/uft.25254863.2017v2n1 231

ABNT:

QUIRINO, R..; GUIMARÃES, S. M. Relações de gênero e divisão sexual do trabalho no meio rural: interlocuções com o movimento social "Marcha das Margaridas". Rev. Bras. Educ. Camp., Tocantinópolis, v. 2, n. 1, p. 231-251, 2017. DOI: http://dx.doi.org/10.20873/uft.2525$\underline{4863.2017 \mathrm{v} 2 \mathrm{n} 1 \mathrm{p} 231}$ 